University of Nebraska - Lincoln

DigitalCommons@University of Nebraska - Lincoln

Faculty Publications from the Harold W. Manter Laboratory of Parasitology

Parapharyngodon duniae n. sp. (Nematoda: Pharyngodonidae) in Phrynohyas venulosa (Anura: Hylidae) from the Área de Conservación Guanacaste, Guanacaste, Costa Rica

Charles R. Bursey

Pennsylvania State University

Daniel R. Brooks

University of Toronto, dnlbrooks@gmail.com

Follow this and additional works at: https://digitalcommons.unl.edu/parasitologyfacpubs

Part of the Parasitology Commons

Bursey, Charles R. and Brooks, Daniel R., "Parapharyngodon duniae n. sp. (Nematoda: Pharyngodonidae) in Phrynohyas venulosa (Anura: Hylidae) from the Área de Conservación Guanacaste, Guanacaste, Costa Rica" (2004). Faculty Publications from the Harold W. Manter Laboratory of Parasitology. 231.

https://digitalcommons.unl.edu/parasitologyfacpubs/231

This Article is brought to you for free and open access by the Parasitology, Harold W. Manter Laboratory of at DigitalCommons@University of Nebraska - Lincoln. It has been accepted for inclusion in Faculty Publications from the Harold W. Manter Laboratory of Parasitology by an authorized administrator of DigitalCommons@University of Nebraska - Lincoln. 


\title{
PARAPHARYNGODON DUNIAE N. SP. (NEMATODA: PHARYNGODONIDAE) IN PHRYNOHYAS VENULOSA (ANURA: HYLIDAE) FROM THE AREA DE CONSERVACIÓN GUANACASTE, GUANACASTE, COSTA RICA
}

\author{
Charles R. Bursey and Daniel R. Brooks* \\ Department of Biology, Pennsylvania State University, Shenango Campus, 147 Shenango Avenue, Sharon, Pennsylvania 16146. e-mail: \\ cxb13@psu.edu
}

\begin{abstract}
Parapharyngodon duniae $\mathrm{n}$. sp. (Nematoda: Pharyngodonidae) in the large intestine of the veined tree frog, Phrynohyas venulosa, from the Area de Conservación Guanacaste in northwestern Costa Rica is described and illustrated. Parapharyngodon duniae $\mathrm{n}$. sp. represents the 34th species assigned to the genus, the 10th species from the Neotropical Realm, and only the third species to parasitize anurans. It is distinguished from the other Neotropical species by having postbulbar ovaries and a prebulbar excretory pore.
\end{abstract}

In an ongoing inventory of eukaryotic parasites of vertebrates of the Area de Conservación, Guanacaste, in northwestern Costa Rica (http://brooksweb.zoo.utoronto.ca/index.html), 122 nematodes of an undescribed species of Parapharyngodon Chatterji, 1933, were collected from the large intestine of 4 veined tree frogs, Phrynohyas venulosa (Laurenti, 1768). Phrynohyas venulosa has wide distribution in Central and South America, ranging from central Mexico through western Ecuador, Venezuela, Trinidad, and Tobago to northeastern Brazil, Bolivia, and northern Argentina (Savage, 2002). To our knowledge, there are only 2 previous reports (Combes and Laurent, 1979; Bursey et al., 2001) of helminths from $P$. venulosa.

Thirty-three species of Parapharyngodon are currently recognized (Bursey and Goldberg, 1999; Bursey and Telford, 2002; Ramallo et al., 2002). Of these, only P. garciae Schmidt and Whittaker, 1975, and P. osteopili Adamson, 1981, parasitize anurans. Three species are found in the Australian Realm, 5 species in the Ethiopian Realm, 3 in the Nearctic Realm, 9 in the Neotropical Realm, 4 in the Oriental Realm, and 9 in the Palaearctic Realm. This article describes the 10th species of Parapharyngodon from the Neotropical Realm.

\section{MATERIALS AND METHODS}

Frogs were collected by hand at night and examined for parasites. Nematodes in the large intestine and rectum were fixed in glacial acetic acid, then preserved and stored in $70 \%$ ethanol, and later cleared in glycerol for further examination and identification. Drawings were made with the aid of a microprojector. Measurements (mean \pm 1 SD, followed by range in parentheses) are given in micrometers, unless otherwise stated.

\section{DESCRIPTION \\ Parapharyngodon duniae n. sp. (Figs. 1-6)}

General: Robust nematodes with prominent annulations beginning at cephalic extremity, continuing to anus. Mouth bounded by 3 bilobed lips. Lateral alae present in males, absent in females. Males without caudal alae; caudal filament directed dorsally. Females with conical tail terminating in short, stiff spike. Eggs with subterminal operculum, containing larvae at morula stage of development.

Received 23 June 2003; revised 4 September 2003; accepted 4 September 2003.

* Department of Zoology, University of Toronto, Toronto, Ontario M5S 3G5, Canada.
Male: Based on 10 mature specimens. Length $1.86 \pm 0.12$ $\mathrm{mm}$ (1.66-2.04), width at level of excretory pore $127 \pm 5$ (122134). Vestibule $15 \pm 3(12-18)$, esophageal corpus $332 \pm 18$ (305-360), esophageal bulb $74 \pm 4$ (67-82) long, $80 \pm 6$ (67$88)$ wide. Nerve ring $135 \pm 6(128-146)$ and excretory pore $605 \pm 19$ (574-638) from anterior end, respectively. Lateral alae beginning near level of esophageal isthmus, gradually increasing in width to 20 , ending about 200 anterior to anus. Annulations about 12 apart. Testis at midbody, flexing posteriorly immediately behind excretory pore. Vas deferens separated from testis by narrow tube. Tail $82 \pm 3$ (79-88) inserted dorsally, reduced to slender appendage. Spicule $46 \pm 4$ (4049) long. Seven caudal papilla, 1 pair ventral, preanal; 1 pair lateral, postanal; 1 median, postanal; 1 pair on caudal appendage. Anterior anal lip echinate.

Female: Based on 10 gravid specimens. Length $4.23 \pm 0.20$ $\mathrm{mm}$ (3.84-4.48), width at vulva $383 \pm 40$ (318-434). Vestibule $15 \pm 3(12-18)$, esophageal corpus $574 \pm 52$ (485-625), bulb $117 \pm 7$ (110-134) long and $115 \pm 7(106-122)$ wide. Nerve ring $159 \pm 22$ (122-183), excretory pore $635 \pm 52$ (536-689), and slightly salient vulva $2,009 \pm 64(1,920-2,110)$ from anterior end, respectively. Proximal half of vagina muscular. Vagina directed dorsally, then posteriorly joining parallel uteri. Uteri extending posteriorly to posterior end of body cavity, flexing forward joining oviducts in midbody region. Ovaries originating in region of esophageal bulb. In older gravid individuals, ovaries extend into corporal region, but not wrapped around esophageal corpus. Eggs subovate, slightly flattened on 1 side, circular in optical cross section, $117 \pm 4$ (110-122) long, 45 \pm 4 (36-49) wide, morula stage of development at deposition. Egg shell thick; surface covered with tiny punctations. Posterior end of body conical, terminating in straight, stiff tail spike 243 \pm 27 (192-288) long. Anus slitlike with slightly salient posterior lip, $486 \pm 54$ (384-576) from end of spike.

\section{Taxonomic summary}

Type host: Phrynohyas venulosa (Laurenti, 1768) (Anura: Hylidae), veined tree frog; male collected on 22 May 1997.

Type locality: Area de Conservación, Guanacaste, Costa Rica $\left(10^{\circ} 57^{\prime} \mathrm{N}, 85^{\circ} 48^{\prime} \mathrm{W}\right)$.

Site of infection: Large intestine.

Type specimens: Holotype-male, U.S. National Parasite Collection, Beltsville, Maryland, USNPC 93494. Allotype-female (USNPC 93495). Paratypes— 9 females, 9 males (USNPC 93496). 

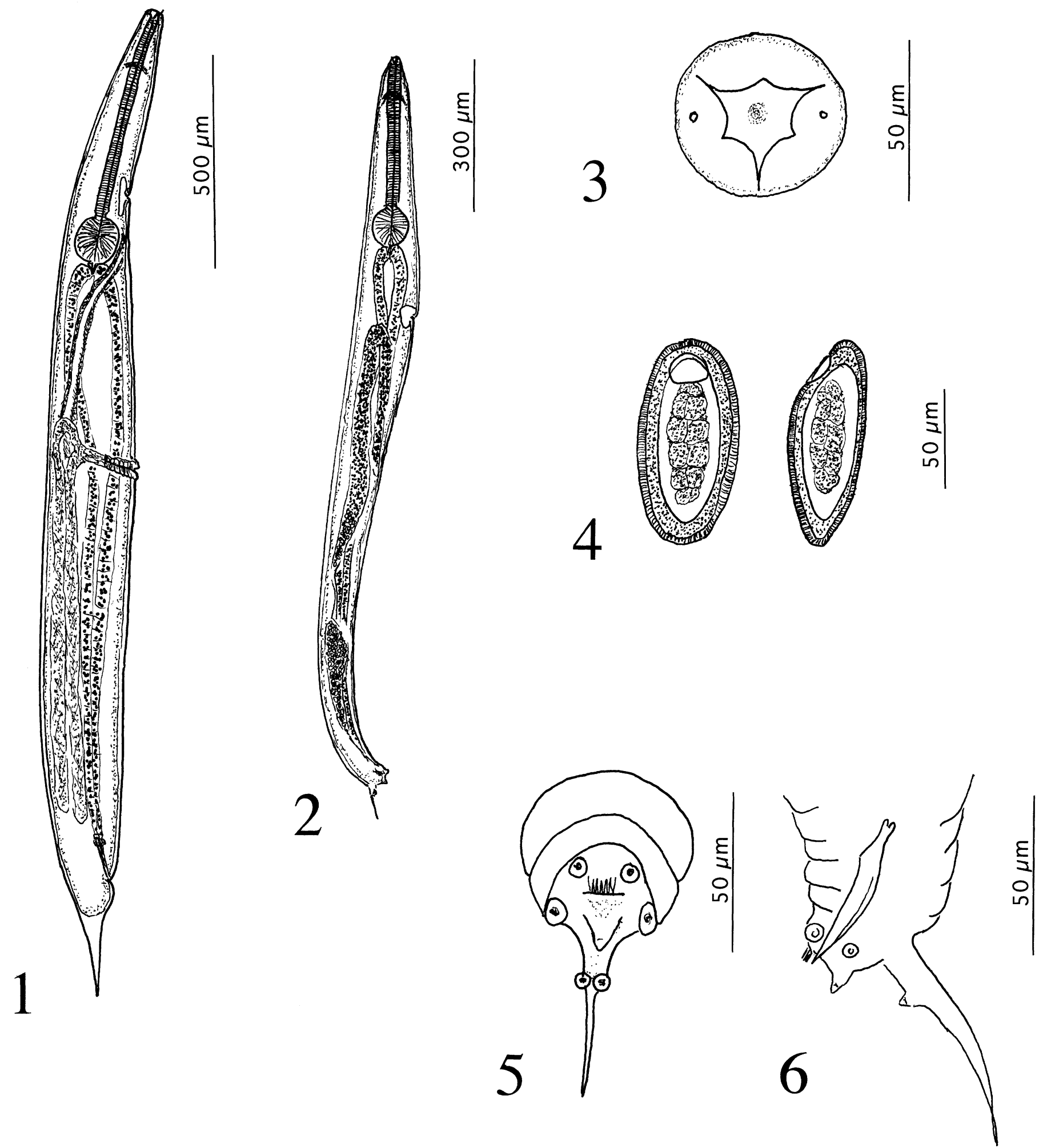

Figures 1-6. Parapharyngodon duniae n. sp. 1. Female, nongravid, entire, lateral view. 2. Male, entire, lateral view. 3. Female, en face view. 4. Eggs, morula stage of development. 5. Male, posterior end, ventral view. 6. Male, posterior end, lateral view.

Etymology: The new species is named after Sra. Dunia Garcia, parataxonomist working in the Area de Conservación Guanacaste, in recognition of her efforts on behalf of the parasite inventory project.

\section{Remarks}

We assigned these specimens to Parapharyngodon based on the morphology of the egg, i.e., a subterminal operculum, and 
a larva in the morula stage of development. The most recent list of Neotropical species of Parapharyngodon is that of Ramallo et al. (2002). Of the Neotropical species, $P$. duniae is most similar to $P$. riojensis Ramallo, Bursey and Goldberg, 2002 , by having an ovary that does not wrap around the esophagus, eggs that are subovate with a thick, punctated shell, and similar placement of caudal papillae (1 pair ventral, preanal; 1 pair lateral, postanal; 1 median, postanal; 1 pair on caudal appendage). These 2 species differ in the location of the excretory pore of the females, posterior to the esophageal bulb in $P$. riojensis and anterior to the esophageal bulb in $P$. duniae. In addition, the spicule of $P$. riojensis is approximately twice the length of that of $P$. duniae (90-110 vs. $40-49$, respectively).

\section{DISCUSSION}

The discovery of $P$. duniae requires that a new couplet be placed in the key of Ramallo et al. (2002) as follows:

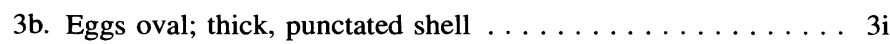
3ia. Female excretory pore posterior to esophageal bulb ...P. riojensis 3ib. Female excretory pore anterior to esophageal bulb ...P. duniae

As stated in the introduction, this study represents the third report of helminth parasites in $P$. venulosa, totaling 4 species. Previous studies listed the monogenean Polystoma lopezromani from Argentina (Combes and Laurent, 1979) and the nematodes Batracholandros spectatus and Physalotera sp. (larvae) from Peru (Bursey et al., 2001).

\section{ACKNOWLEDGMENTS}

We are grateful to the scientific and technical staff of the ACG for support of this study, in particular: Elda Araya, Roger Blanco, Carolina Cano, Maria Marta Chavarría, Felipe Chavarría, Roberto Espinoza, Dunia Garcia, Guillermo Jimenez, Elba Lopez, Sigifredo Marin, Alejandro Masis, Calixto Moraga, Fredy Quesada, and Petrona Rios. Thanks also to Dan Janzen and Hallwachs, scientific advisers to the ACG, for their support. This study was funded by a research grant from the Natural Sciences and Engineering Research Council (NSERC) of Canada to D.R.B.

\section{LITERATURE CITED}

BURSEY, C. R., AND S. R. GoldBERG. 1999. Parapharyngodon japonicus sp. n. (Nematoda: Pharyngodonidae) from the Japanese clawed salamander, Onychodactylus japonicus (Caudata: Hynobiidae), from Japan. Journal of the Helminthological Society of Washington 66: $180-186$.

— — - AND J. R. PARMEleE. 2001. Gastrointestinal helminths of 51 species of anurans from Reserva Cuzco Amazónico, Peru. Comparative Parasitology 68: 21-35.

, AND S. R. TELFORD JR. 2002. Parapharyngodon ocalaensis $\mathbf{n}$. sp. (Nematoda: Pharyngodonidae) from the sand skink, Neoseps reynoldsi (Scincidae), of Florida. Journal of Parasitology 88: 929931.

Combes, C., AND R. F. LAURENT. 1979. Les monogenes Polystomatidae de Republique Argentine: Description de deux nouvelles especies et essai de synthese. Revista Iberica de Parsitologia 79: 545-557.

Ramallo, G., C. R. Bursey, and S. R. Goldberg. 2002. Parapharyngodon riojensis $\mathrm{n}$. sp. (Nematoda: Pharyngodonidae) from the lizard Phymaturus punae (Squamata: Iguania: Liolaemidae) from northwestern Argentina. Journal of Parasitology 88: 979-982.

Savage, J. M. 2002. The amphibians and reptiles of Costa Rica: A herpetofauna between two continents, between two seas. The University of Chicago Press, Chicago, Illinois. 934 p. 